\title{
Protective effects of tropisetron on cerulein-induced acute pancreatitis in mice
}

\author{
Reza Rahimian ${ }^{\mathrm{a}, \mathrm{b}, 1}$, Mohammad Reza Zirak ${ }^{\mathrm{c}, 1}$, Mohammad Seyedabadi $^{\mathrm{d}, *}$, \\ Mojtaba Keshavarz ${ }^{\mathrm{d}, \mathrm{e}}$, Amir Rashidian ${ }^{\mathrm{b}}$, Sareh Kazmi ${ }^{\mathrm{f}}$, Amir Hossein Jafarian ${ }^{\mathrm{g}}$, \\ Gholamreza Karimi $^{\mathrm{h}}$, Kazem Mousavizadeh ${ }^{\mathrm{i}, * *}$

\footnotetext{
a Department of Psychiatry and Neuroscience, Faculty of Medicine, Université Laval, Québec City, Québec, Canada

${ }^{\mathrm{c}}$ Department of Pharmacodynamics and Toxicology, School of Pharmacy, Mashhad University of Medical Sciences, Mashhad, Iran

e Shiraz Neuroscience Research Center, Shiraz University of Medical Sciences, Shiraz, Iran

${ }^{\mathrm{f}}$ Department of Anatomical Sciences, School of Medicine, Iran University of Medical Sciences, Tehran, Iran

g Cancer Molecular Pathology Research Center, School of Medicine, Mashhad University of Medical Sciences, Mashhad, Iran

h Pharmaceutical Research Center, School of Pharmacy, Mashhad University of Medical Sciences, Mashhad, Iran

Sciences, Tehran, Iran
} \\ ${ }^{\mathrm{b}}$ Department of Pharmacology, School of Medicine, Tehran University of Medical Sciences, Tehran, Iran \\ d Department of Pharmacology, School of Medicine, Bushehr University of Medical Sciences, Bushehr, Iran \\ ${ }^{\mathrm{i}}$ Cellular and Molecular Research Center and Department of Molecular Medicine, Faculty of Advanced Technologies in Medicine, Iran University of Medical
}

\section{A R T I C L E I N F O}

\section{Article history:}

Received 21 February 2017

Received in revised form 17 June 2017

Accepted 19 June 2017

\section{Keywords:}

Acute pancreatitis (AP)

Cerulein

Tropisetron

Mice

Cytokines

\section{A B S T R A C T}

Acute pancreatitis (AP) causes morbidity and mortality. The aim of the present study was to investigate the protective effect of tropisetron against AP induced by cerulein.

Cerulein $(50 \mu \mathrm{g} / \mathrm{kg}, 5$ doses) was used to induce AP in mice. Six hours after final cerulein injection, animals were decapitated. Hepatic/pancreatic enzymes in the serum, pancreatic content of malondialdehyde (MDA), pro-inflammatory cytokines and myeloperoxidase (MPO) activity were measured.

Tropisetron significantly attenuated pancreatic injury markers and decreased the amount of elevated serum amylase, lipase, alanine aminotransferase (ALT), aspartate aminotransferase (AST), MPO activities and pro-inflammatory cytokines levels caused by AP in mice. Tropisetron didn't affect the pancreatic levels of MDA.

Our results suggest that tropisetron could attenuate cerulein-induced AP by combating inflammatory signaling. Further clinical studies are needed to confirm its efficacy in patients with AP.

(C) 2017 Elsevier Masson SAS. All rights reserved.
Abbreviations: ALT, alanine aminotransferase; AP, acute pancreatitis; AST, aspartate aminotransferase; CLP, cecal ligation and puncture; DM, diabetes mellitus; ELISA, enzyme linked immunosorbent assay; ERCP, endoscopic retrograde cholangiopancreatography; IL-1 $\beta$, Interleukin 1 beta; IL-6, interleukin 6; IL-8 interleukin 8; IQR, interquartile range; $\mathrm{I} \kappa \mathrm{B} \alpha$, Inhibitor kappa B-alpha; MAPK, mitogen-activated protein kinase; $\mathrm{m}-\mathrm{CPBG}$, meta chlorophenylbiguanide; MDA malondialdehyde; NAFT, nuclear factor of activated T cells; NF- $\kappa$, nuclear factor$\kappa B$; PPAR $\gamma$, peroxisome proliferator activated receptor gamma; SDS, sodium dodecyl sulfate; TBA, thiobarbituric acid; TNF- $\alpha$, Tumor necrosis factor alpha; $\alpha 7$ nAChR, alpha7 nicotinic acetylcholine receptor.

* Corresponding author at: Department of Pharmacology, School of Medicine, Bushehr University of Medical Sciences, Bushehr, Iran.

** Corresponding author at: Cellular and Molecular Research Center, Iran University of Medical Sciences (IUMS), Hemmat Highway, Tehran, Iran.

E-mail addresses: seyedabadi1981@gmail.com (M. Seyedabadi), mousavik@gmail.com (K. Mousavizadeh).

1 These authors contributed equally to this work.

\section{Introduction}

Acute pancreatitis (AP) is an inflammatory disorder of the pancreas and the leading cause of hospitalization among different types of gastrointestinal disorders worldwide [1]. Epidemiologic analysis revealed that hospital admissions for AP increased from 40 per 100,000 in 1998 to 70 per 100,000 in 2002 [2]. The molecular mechanisms underlying AP are not fully understood yet, but it has been shown that inflammatory mediators play an important role in the progression and severity of AP [3]. Acinar cell injury caused by factors like gallstones in the distal common bile duct, alcohol abuse and endoscopic retrograde cholangiopancreatography (ERCP) led to release of digestive enzymes [4,5]. Subsequent to acinar cell injury, inflammatory cytokines including interleukin 6 (IL-6), interleukin 8 (IL-8), Tumor necrosis factor alpha (TNF- $\alpha$ ) are 
produced within pancreas [6]. These cytokines can induce apoptosis in acinar cells and stimulate neutrophils to be recruited at the site of inflammation [7,8]. Furthermore, pancreatic enzymes could reach distant organs like lung and live through systemic circulation and cause injury [6]. For example, pancreatic elastase induced liver inflammation and upregulation of hepatic TNF predominantly within Kupffer cells [9,10]. Also, it was shown that interleukin-1 and TNF can increase the expression of other cytokines and related genes, which finally resulted in systemic inflammatory response to acute pancreatitis and the subsequent organ failure [6,11].

Current therapies including antisecretory agents, protease inhibitors, antioxidants, immunomodulators and etc., are insufficient for treatment of this disease. So, there is a pressing need for more effective therapies [12].

Tropisetron, a $5-\mathrm{HT}_{3}$ receptor antagonist, is widely used to treat chemotherapy associated emesis [13]. Anti-inflammatory and antioxidant aspects of tropisetron have been shown in various peripheral and central inflammatory settings [14], including experimental colitis[15], cisplatin-induced nephrotoxicity [16], ischemic stroke [17], beta-amyloid-induced neuroinflammation [18] and animal model of multiple sclerosis[19]. Furthermore, in a rat model of cecal ligation and puncture (CLP)- induced sepsis tropisetron administration significantly inhibited TNF- $\alpha$ and IL-6 overproduction in serum [20]. Although the exact mechanisms underlying anti-inflammatory effects of tropiseton have not been identified yet, different canonical pathways involved in inflammation such as Nuclear factor- $\kappa \mathrm{B}(\mathrm{NF}-\kappa \mathrm{B})$, calcineurin, mitogenactivated protein kinase (MAPK), peroxisome proliferator-activated receptor gamma (PPAR $\gamma$ ) and Alpha7 nicotinic acetylcholine receptor $(\alpha 7 \mathrm{nAChR})$ have been shown as targets of tropisetron [14].

Regarding the remarkable anti-inflammatory properties of tropisetron and its wide therapeutic window, it would be plausible to investigate the protective aspects of tropisetron in an experimental model of AP. In this context the possible protective actions of tropisetron was studied in cerulein-induced AP in mice.

\section{Materials and methods}

\subsection{Animals}

Male NMR mice weighing 25-30 g were randomly assigned to 3 experimental groups (each group contains 6 animals). The animals were housed for one week before the experiments to acclimatize to new conditions. The experimental procedures were approved by the Ethics Committee of Iran University of Medical Sciences, Tehran, Iran in accordance with the Standards for the Care and Use of Laboratory Animals. Animals were kept in a room with 12 -h light/12-h dark cycle and $22-24^{\circ} \mathrm{C}$.

\subsection{Induction of pancreatitis}

Acute pancreatitis was induced by cerulein $(50 \mu \mathrm{g} / \mathrm{kg}$, ip, 5 doses at hourly intervals) [21]. In treatment group, tropisetron ( $2 \mathrm{mg} / \mathrm{kg}$, ip) was administered twice at the intervals of one and six hours after the first cerulein administration. Control group received normal saline in the same manner.

Six hours after the last cerulein injection, animals were euthanized, blood samples were collected and pancreases removed and snap frozen in liquid nitrogen and then kept at $-80^{\circ} \mathrm{C}$ for later biochemical measurements. Blood samples were used to determine the serum amylase and lipase activities. A portion of pancreases was fixed in $10 \%$ formalin for histopathological evaluation.

\subsection{Biochemical analysis}

The serum amylase, lipase, aspartate aminotransferase (AST) and alanine aminotransferase (ALT) activities were determined using the commercially available kits (Pars-Azmun Co. Tehran, Iran) [22].

\subsection{Determination of lipid peroxidation}

Malondialdehyde (MDA) level was measurement as an indicator of lipid peroxidation with thiobarbituric acid (TBA) based reaction [23]. Briefly, the pancreas tissue was homogenized in $1.15 \% \mathrm{KCl}$ solution. Then, $0.1 \mathrm{ml}$ of the homogenate was added to a reaction solution containing $0.2 \mathrm{ml}$ of sodium dodecyl sulfate (SDS) (8.1\%), $1.5 \mathrm{ml}$ of acetic acid (20\%), $1.5 \mathrm{ml}$ of TBA $(0.8 \%)$ and $0.7 \mathrm{ml}$ of distilled water. Samples were boiled for $30 \mathrm{~min}$ at $95^{\circ} \mathrm{C}$. TBAtreated samples were mixed with $n$-butanol and centrifuged at $3000 \mathrm{~g}$ for $10 \mathrm{~min}$. The absorbance of the supernatant was read at $532 \mathrm{~nm}$ with a spectrophotometer. MDA level was expressed as $\mu \mathrm{M} / 100 \mathrm{~g}$ tissue.

\subsection{Determination of total myeloperoxidase activity (MPO) activity}

MPO activity, an indicator of neutrophil sequestration in the pancreas, was determined as previously decribed [24]. Concisely, pancreatic tissues were homogenized in $10 \mathrm{mM}$ potassium phosphate buffer ( $\mathrm{pH} 7.4)$ containing $0.5 \%(\mathrm{w} / \mathrm{v})$ hexadecyl trimethyl ammonium bromide ( $50 \mathrm{mg}$ tissue $/ \mathrm{mL}$ ). The homogenates were centrifuged for $30 \mathrm{~min}$ at $20,000 \mathrm{~g}$ at $4{ }^{\circ} \mathrm{C}$. After that, the supernatant was allowed to react with a solution containing tetramethyl benzidine $(1.6 \mathrm{mM})$ and hydrogen peroxide $(0.1 \mathrm{mM})$. The rate of change in absorbance was measured spectrophotometrically at $650 \mathrm{~nm}$. Myeloperoxidase activity was defined as the quantity of enzyme degrading $1 \mathrm{mmol}$ peroxide/min at $37^{\circ} \mathrm{C}$. Values were expressed as MPO in units/g wet tissue.

\subsection{Histopathological examination and scoring}

After decapitating of mice, a portion of pancreases was fixed in $10 \%$ formalin for $24-48 \mathrm{~h}$. Then, pancreases were embedded in paraffin to be cut into $5 \mu \mathrm{m}$-thick sections and dying with hematoxylin and eosin. Finally, a pathologist observed the tissue sections under light microscope blindly and scored them (1-4) through evaluating the following criteria: edema, pro-inflammatory cell infiltration, acinar vacuolization and necrosis (one is normal and 4 is severe) [25].

\subsection{Determination of inflammatory mediators}

To determine the inflammatory cytokine levels, the pancreatic tissues were homogenized as described by previously [26]. Briefly, a lysis buffer was prepared containing $200 \mathrm{mM} \mathrm{NaCl}, 5 \mathrm{mM}$ EDTA, $10 \mathrm{mM}$ tris, $10 \%$ glycerin and $1 \mathrm{mM}$ PMSF. Next, one tablet of protease inhibitor cocktail was added for $10 \mathrm{ml}$ of lysis buffer. Finally, the $\mathrm{pH}$ was adjusted to 7.4. After that, we added $200 \mu \mathrm{l}$ lysis buffer to $10 \mathrm{mg}$ tissue before homogenization. Samples were centrifuged twice ( $1500 \mathrm{~g}$ at $4{ }^{\circ} \mathrm{C}$ for $15 \mathrm{~min}$ ) to avoid contamination of cell debris. The supernatant was used for measurement of cytokines. Enzyme-linked immunosorbent assay (ELISA) kits were used for measurement of TNF- $\alpha$, Interleukin 1 beta (IL-1 $\beta$ ) in the pancreas samples (duplicate experiments).

\subsection{Statistical analysis}

Histologic damage score is presented as median \pm interquartile range (IQR). For analysis of this factor, Kruskal-Wallis test followed 
A
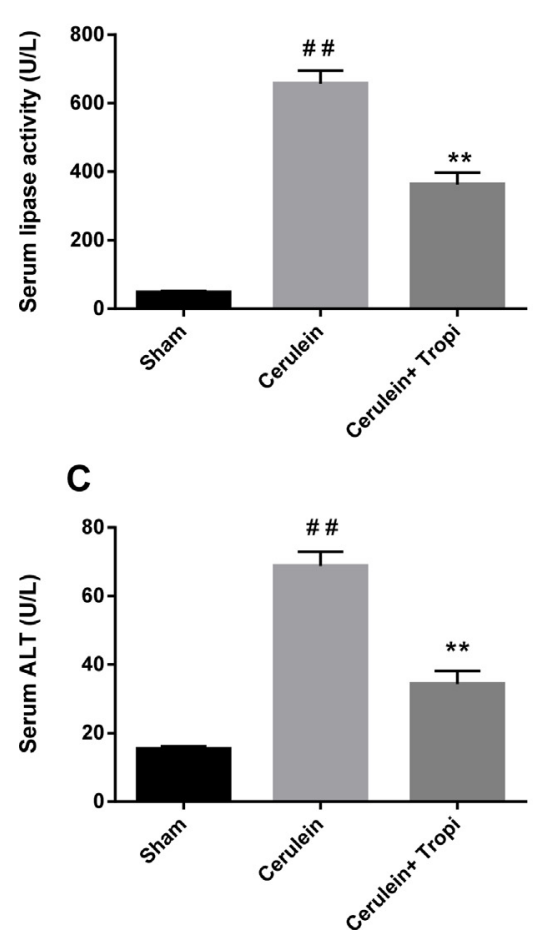

B

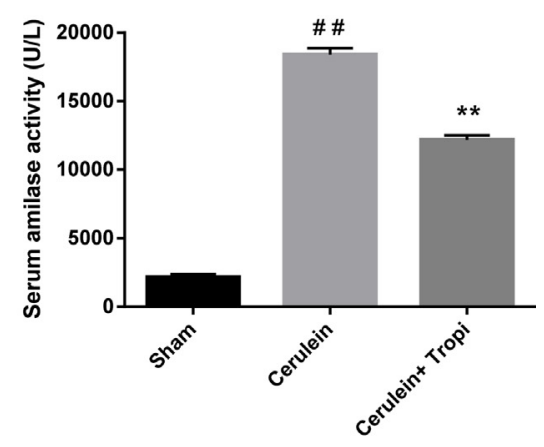

D

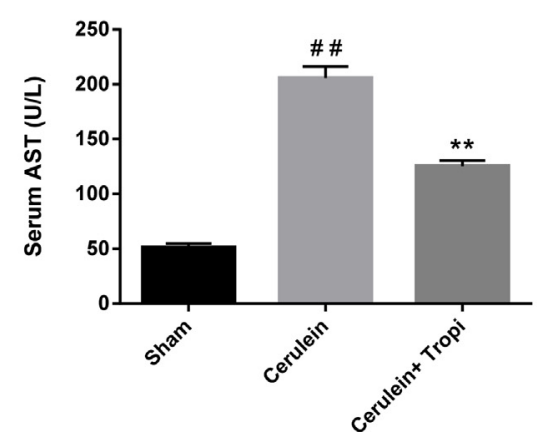

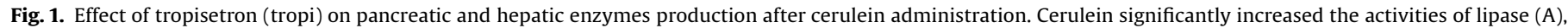

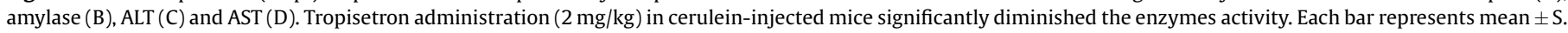
E.M. \# $\mathrm{P}<0.05$, versus the sham group; ${ }^{*} \mathrm{p}<0.05$, versus cerulein group. \#\# and ${ }^{* *}, \mathrm{p}<0.001$ ( $\mathrm{n}=6$ per group).

by Dunn's as a post-hoc test was used. Other results were expressed as mean \pm SEM and statistical differences were analyzed by one-way ANOVA followed by Tukey post-hoc test. P value $<0.05$ was considered significant.

\section{Results}

\subsection{Effects of tropisetron on pancreatic and hepatic enzymes}

The levels of serum amylase and lipase were increased following induction of AP by cerulein. It has been shown that the levels of hepatic enzymes such as AST and ALT increase in patients with AP [27]. In fact, liver injury was assessed in AP as a clinical prognostic indicator and it is used to predict the severity of acute pancreatitis [28].

Similarly, in our study serum levels of AST and ALT were significantly increased in cerulein-treated animals. As depicted in Fig. 1.A-D, treatment of animals with tropisetron significantly reduced the elevated levels of pancreatic and hepatic enzymes $(\mathrm{p}<0.001)$.

\subsection{Effect of tropisetron on cerulein-induced oxidative stress and leukocytes infiltration}

During AP, neutrophils are recruited from the circulation to pancreases and enhanced the production of reactive oxygen species (ROS) and pro-inflammatory cytokines in response to an inflammatory stimulation [8]. In the present study, pancreatic MDA levels notably increased in mice treated with cerulein while tropisetron had no effect on lipid peroxidation caused by cerulein (data not shown).

MPO activity was measured as an index of neutrophil infiltration. Cerulein significantly $(p<0.001)$ elevated the MPO activity as an indicator of neutrophil sequestration in the pancreas.
This change was reversed by treatment of animals with tropisetron $(2 \mathrm{mg} / \mathrm{kg}$ ) (Fig. 2). This effect corroborates our pervious findings showed that tropisetron diminished MPO activity in inflamed colon via $5-\mathrm{HT}_{3}$ receptor dependent and non-dependent mechanisms [15].

\subsection{Effects of tropisetron on inflammatory cytokines}

Cerulein administration induces activation of the transcription factor NF- $\kappa$ B. This effect is accompanied by a notable decrease of inhibitory protein, Inhibitor kappa B-alpha (ІкB $\alpha$ ) content. Therefore, NF- $\kappa B$ activation has a pivotal role in controlling the inflammatory signaling that happens in cerulean-induced AP [29].

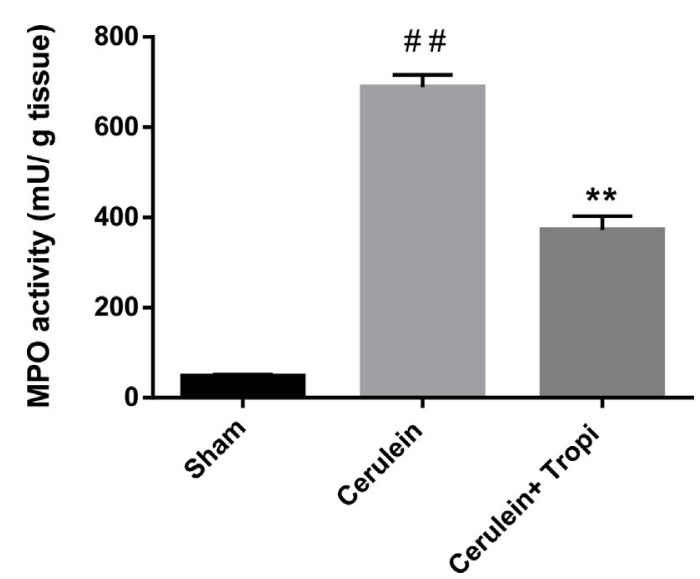

Fig. 2. Effect of tropisetron (tropi) on pancreatic MPO activity during AP. Tropisetron treatment reduced the MPO activity. Each bar represents mean \pm S.E. $\mathrm{M}$. \# $\mathrm{P}<0.05$, versus the sham group; * $\mathrm{p}<0.05$, versus cerulein group. \#\# and ${ }^{* *}$, $\mathrm{p}<0.001$ ( $\mathrm{n}=6$ per group). 
NF- $\kappa B$ activation during AP leads to overproduction of proinflammatory cytokines such as TNF- $\alpha$ and IL- $1 \beta$. These cytokines increase the recruitment of neutrophils into the pancreas. Increased levels of inflammatory cytokines have been observed in both acute human and experimental pancreatitis [30,31]. In our hands cerulein administration enhanced pancreatic levels of TNF$\alpha$ and IL- $1 \beta$ by 5 -fold compared to saline treated mice. As shown in Fig. 4, tropisetron significantly decreased the levels of TNF- $\alpha$ (p $<0.001)$ and IL-1 $\beta(p=0.001)$ in pancreas tissue (Fig. 3A, B) indicating its potent anti-inflammatory aspects. These results confirm different experimental findings revealed tropisetron administration exerts notable protective effects in peripheral and central inflammatory conditions such as experimental inflammatory bowel disease[15], experimental autoimmune encephalomyelitis[19], stroke [17] and beta-amyloid-induced neuroinflammation [18]. The protective actions of tropisetron in AP could be a classical $5-\mathrm{HT}_{3}$ receptor dependent effects as recently ondansetron, another $5-\mathrm{HT}_{3}$ receptor antagonists, was shown to decrease serum levels of amylase and lipase, cell infiltration and cytokine production in cerulean-induced AP [32].

\subsection{Effects of tropisetron on pancreas histological changes associated} with cerulein

Administration of cerulein $(50 \mu \mathrm{g} / \mathrm{kg} / \mathrm{h}, \times 5$, i.p.) resulted in massive pancreatic injury characterized by leucocytes infiltration, edema and acinar cell necrosis (Fig. 4B); however, co-treatment of tropisetron and cerulein in mice improved histopathologic damages compared to cerulein group (Fig. 4C). Fig. 4D presents histological scoring of pancreatic tissue damage in normal mice and cerulein-treated mice in presence or absence tropisetron. Tropisetron reduced histological damages compared to cerulein group but the effect was not statistically significant.

\section{Discussion}

AP is an inflammatory disorder of pancreas which appears to be rising during last decades and causes a significant mortality [2]. Up to now, a lot of components were investigated to attenuate this condition but few were effective enough to be used in patients, so researches continue to find safe and effective compounds to treat AP [33].

We showed for the first time that tropisetron $(2 \mathrm{mg} / \mathrm{kg})$ diminished cerulein-induced AP. Induction of pancreatitis by cerulein is a well-established model of AP and mimics histopathological characteristic of human pancreatitis [3]. In both animal and clinical studies, levels of liver and pancreatic enzymes increased in AP $[1,21]$. In this study, IP injection of cerulean caused elevation of these enzymes and administration of tropisetron $(2 \mathrm{mg} / \mathrm{kg}$ ) resulted in significant reduction of pancreatic enzymes activities.

It has been demonstrated that pancreatic enzymes could access the systemic circulation as the result of inflammatory changes in the pancreas and retroperitoneum. They cause damage to distant organs such as the liver through producing the inflammatory mediators [28]. In this context, cerulein administration led to liver injury shown by the increase in AST and ALT while tropisetron significantly decreased cerulein associated increase of hepatic enzymes such as ALT and AST. MPO activity is an indicator of neutrophils which recruits into pancreas [8]. At the early stage of $\mathrm{AP}$, damage to the pancreatic cell leads to the release of inflammatory cytokines which cause infiltration of neutrophils into the pancreas. The activated neutrophils release a huge amount of oxidants and cytotoxic agents which further exacerbates the local damage to the pancreatic tissues. In the present study, we observed that the administration of tropisetron alleviated the cerulein-induced pancreatic MPO activity. This effect is similar to those we observed in the experimental model of IBD [34]. Furthermore, an earlier study showed that pro-inflammatory cytokines play a critical role in AP, probably via inducing deleterious leukocyte accumulation within the pancreas [29]. These inflammatory cytokines have been reported to be involved in the pathogenesis of AP. Tropisetron significantly inhibited cerulein-induced inflammatory cytokines including TNF- $\alpha$ and IL-1 $\beta$ production.

The findings of the present study confirmed our previous findings that tropisetron had anti-inflammatory aspects in different inflammatory context [15]. Tropisetron notably decreased renal injury and content of pro-inflammatory cytokines in mice treated with cisplatin [16]. It has been shown that tropisetron could inhibit IL- $1 \beta / \mathrm{TNF} \alpha$ release through preventing the phosphorylation and activation of the p38 MAPK in human primary monocytes [35]. This protein is involved in posttranscriptional regulation of the inflammatory cytokines [36] and its activity has been shown to increase dose-dependently following a single injection of cerulein in pancreatic tissue [37]. Liu et al. demonstrated that tropisetron ( 1 or $3 \mathrm{mg} / \mathrm{kg}$ ) can diminish inflammatory cell responses and organ damage caused by traumahemorrhage [38]. In contrast with the previous study, they reported that the protective effect of tropisetron was reversed by co-administration of the p38 MAPK inhibitor (SB-203580) after trauma-hemorrhage. They concluded the salutary effects of tropisetron are mediated through p38 MAPK-dependent HO-1 expression [38]. Apparently, results of the two mentioned study are in opposite of each other but it has been proved that p38 MAPK pathway is involved both anti-inflammatory and pro-inflammatory processes [39]. P38 pathway controls the expression of
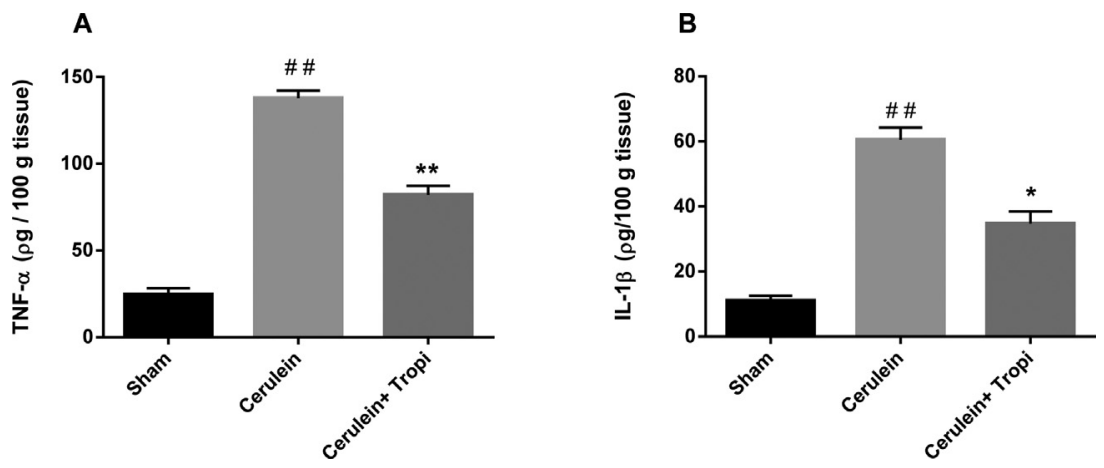

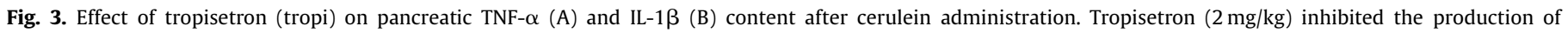

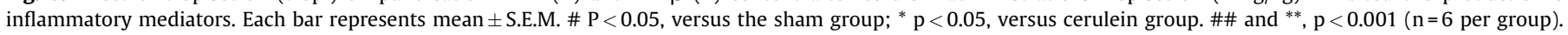



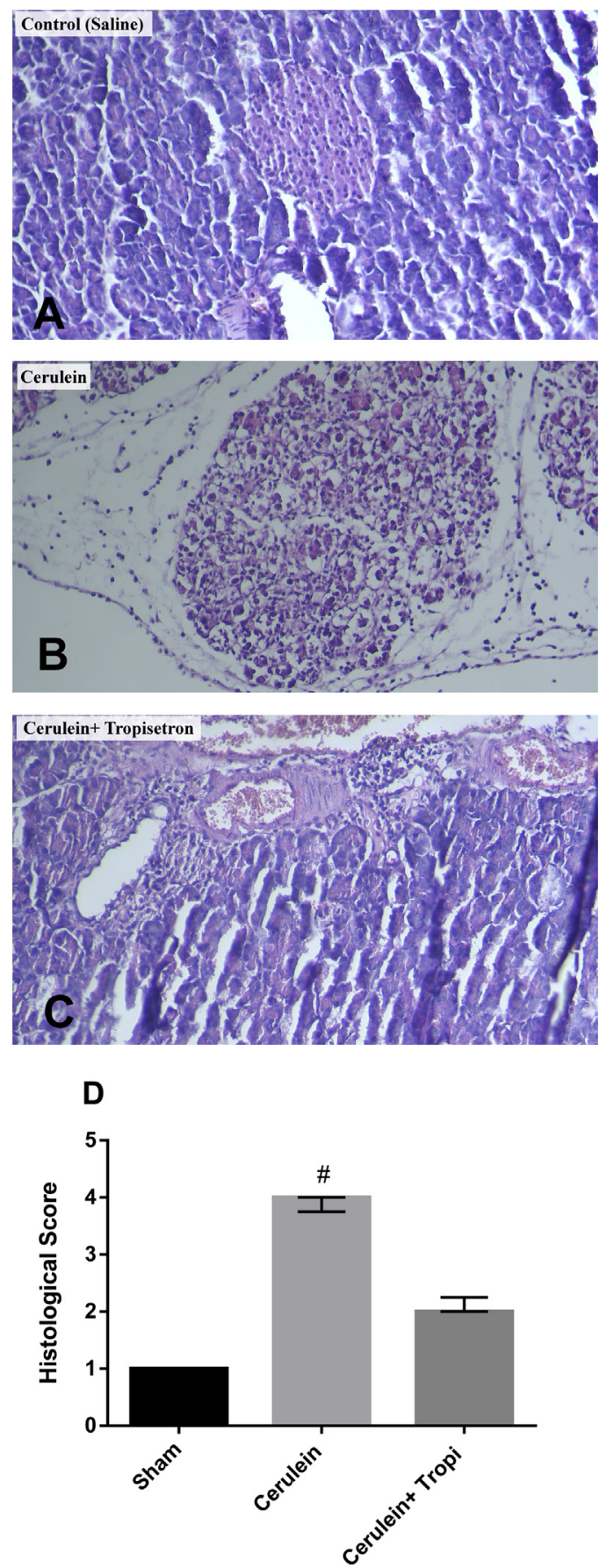

Fig. 4. Effect of tropisetron on histological changes induced by cerulein.

A) Section from mice pancreas with normal histopathologic features. B) Section from pancreas of cerulein-treated mice showing severe edema, inflammatory cell infiltration and focal necrosis. C), Section from mice treated with cerulein and tropisetron shows mild leucocytes infiltration without tissue necrosis. Hematoxylin \& Eosin (H\&E) staining was used, $\times 400$. Tropisetron improved damage scores in comparison to cerulein-treated mice (D). Data of histopathologic score are reported as medians $\pm I Q R$. \# $P<0.05$, versus the sham group; ${ }^{*} \mathrm{p}<0.05$, versus cerulein group. ( $n=6$ per group).

important anti-inflammatory factors which limit inflammation as well as pro-inflammatory cytokines [40]. Collectively, it seems that tropisetron blocks p38 MAPK for a short time because it has been suggested that long-term blockade of the pathway has limited anti-inflammatory effect [40].

Epigastric or left upper quadrant pain is an early symptom of AP and usually, patients with AP suffer from severe pain which radiates to the back, chest, or flanks [2,41]. Analgesic aspects of tropisetron could attenuate AP associate complications such as pain. Interestingly both experimental and clinical studies suggest that $5-\mathrm{HT}_{3}$ receptor antagonists are effective in chronic pain reduction, especially in situations associated with inflammatory origin. Okamoto et al. have shown that systemic and local administrations of tropisetron produce antinociceptive effects, mainly in the late phase in the animal model of formalin test [42]. In a randomized clinical trial, Mei et al. reported that a single-dose intravenous administration of tropisetron significantly alleviates early postoperative pain in women undergoing gynecological laparoscopies compared with those receiving placebo [43]. Likewise, Intrathecal administration of tropisetron in rats with spinal cord injury, decreased hyperalgesia and mechanical allodynia [44].

High blood glucose is found in patients with AP, especially in those with necrotizing pancreatitis [45]. Moreover, the findings of a recent meta-analysis indicated that patients with AP form almost $40 \%$ of newly diagnosed prediabetes or diabetes mellitus (DM) after discharge from the hospital, and it doubles the risk of DM over 5 years [46]. Interestingly, both in vivo and in vitro studies indicate that tropisetron has therapeutic potential to be control high blood glucose levels. [47]. It has been shown that administration of ondansetron, a 5- $\mathrm{HT}_{3}$ receptor antagonist, reduced elevated level of blood glucose in stressed rats stimulated by meta-chlorophenylbiguanide (m-CPBG) [48]. Another report indicated that tropisetron is able to enhance the insulin release in the beta-cell line (INS-1) [49], especially in presence of serotonin. Serotonin reduced the glucose-stimulated release of insulin in a concentration-dependent manner, while tropisetron abolished this inhibition. It shows the involvement of $5-\mathrm{HT}_{3}$ receptors in tropisetroninduced insulin secretion [49]. The exact mechanism concerning secretagogue action of $5-\mathrm{HT}_{3}$ antagonists is still unknown to a large extent. However, classical insulin secreting agents (sulfonylureas) block $\mathrm{K}_{\mathrm{ATP}}$ channels causes depolarization, $\mathrm{Ca}^{2+}$ entry and insulin secretion but $5-\mathrm{HT}_{3}$ antagonists reduce cation influx, in particular $\mathrm{Ca}^{2+}$. Furthermore, no hypoglycemic effect has been reported with therapeutic doses of $5-\mathrm{HT}_{3}$ receptor antagonists $[13,50]$. Fascinatingly, cytosolic calcium concentration regulates protease activation in acinar cells and also calcineurin, a $\mathrm{Ca}^{2+}$-calmodulin dependent serine/threonine protein phosphatase, which is critical for numerous cellular processes and calcium-dependent signal transduction pathways [51,52]. Nuclear factor of activated T cells (NFAT) transcription factor is an important downstream target of calcineurin [53].

it has been shown that pharmacologic inhibition of NFAT signaling resulted in reduction of AP-induced activation of trypsinogen, systemic inflammation and tissue damage, as well as neutrophil recruitment in the pancreas [52]. In in vivo model, we and others showed that $5-\mathrm{HT}_{3}$ receptor antagonist, tropisetron has anti-inflammatory effects by inhibiting calcineurin/NFAT signaling pathway in neurons, lymphocytes and myocardiocytes [54-56].

\section{Conclusion}

Several 5- $\mathrm{HT}_{3}$ receptor dependent and non-dependent mechanisms might contribute to the beneficial effects with tropisetroni in experimental AP; I; inhibition of the p38 MAPK, which is involved in the post-transcriptional regulation of different cytokines such as TNF- $\alpha$ and IL-1 $\beta$ [35]. II; Tropisetron bears an electron rich indole ring in its structure and serves as an electron donor, thereby, it has notable antioxidant properties [13,57]. III; Tropisetron is the partial agonist of $\alpha 7 \mathrm{nAChR}$ which could regulate immune cells activity like macrophages via inhibition of NF- $\mathrm{B}$ nuclear translocation [58-60]. It has been clearly shown that increased NF- $\kappa \mathrm{B}$ activity lead to rise in the cytokine gene 
expression, leukocyte infiltration, and inflammation which play a pivotal role in initiation and severity of AP [61]. IV; Tropisetron could increase PPAR $\gamma$ activity and consequently activate antiinflammatory pathways downstream of PPAR $\gamma$ [38].

In conclusion, our findings suggest that tropisetron has the potential to be used for the treatment of AP; however, further clinical investigations are required to confirm its safety and efficacy.

\section{Conflict of interest}

The authors declare no conflict of interest.

\section{Acknowledgements}

Financial support for this study was provided by Iran University of Medical Sciences (IUMS), and Bushehr University of Medical Sciences, Bushehr, Iran. The authors are very grateful to Dr. Abolfazl Shakeri for revision of our manuscript.

\section{References}

[1] P.G. Lankisch, M. Apte, P.A. Banks, Acute pancreatitis, Lancet 386 (9988) (2015) 85-96, doi:http://dx.doi.org/10.1016/S0140-6736(14)60649-8.

[2] S. Tenner, J. Baillie, J. DeWitt, S.S. Vege, American college of gastroenterology guideline: management of acute pancreatitis, Am. J. Gastroenterol. 108 (9) (2013) 1400-1415, doi:http://dx.doi.org/10.1038/ajg.2013.218.

[3] P.R. Lima, T.S. de Melo, K.M. Carvalho, I.B. de Oliveira, B.R. Arruda, G.A. de Castro Brito, V.S. Rao, F.A. Santos, 8-cineole (eucalyptol) ameliorates cerulein-induced acute pancreatitis via modulation of cytokines, oxidative stress and NF-kappaB activity in mice, Life Sci. 92 (24-26) (2013) 1195-1201, doi:http://dx.doi.org/ $10.1016 /$ j.lfs.2013.05.009.

[4] G.-J. Wang, C.-F. Gao, D. Wei, C. Wang, S.-Q. Ding, Acute pancreatitis: etiology and common pathogenesis, World J. Gastroenterol. 15 (12) (2009) 1427-1430, doi:http://dx.doi.org/10.3748/wjg.15.1427.

[5] J.E. Abela, C.R. Carter, Acute pancreatitis-a review, Surgery (Oxford) 28 (5) (2010) 205-211, doi:http://dx.doi.org/10.1016/j.mpsur.2010.01.002.

[6] N. Zyromski, M.M. Murr, Evolving concepts in the pathophysiology of acute pancreatitis, Surgery 133 (3) (2003) 235-237, doi:http://dx.doi.org/10.1067/ msy.2003.87.

[7] D. Wu, Y. Zeng, Y. Fan, J. Wu, T. Mulatibieke, J. Ni, G. Yu, R. Wan, X. Wang, G. Hu, Reverse-migrated neutrophils regulated by JAM-C are involved in acute pancreatitis-associated lung injury, Sci. Rep. 6 (2016) 20545, doi:http://dx.doi. org/10.1038/srep20545.

[8] Z.-W. Yang, X.-X. Meng, P. Xu, Central role of neutrophil in the pathogenesis of severe acute pancreatitis, J. Cell. Mol. Med. 19 (11) (2015) 2513-2520, doi: http://dx.doi.org/10.1111/jcmm.12639.

[9] M.M. Murr, J. Yang, A. Fier, P. Kaylor, S. Mastorides, J.G. Norman, Pancreatic elastase induces liver injury by activating cytokine production within Kupffer cells via nuclear factor-кB, J. Gastrointest. Surg. 6 (3) (2002) 474-480, doi: http://dx.doi.org/10.1016/s1091-255x(01)00071-3.

[10] J. Yang, A. Fier, Y. Carter, G. Liu, P.K. Epling-Burnette, F. Bai, T.P. Loughran, S. Mastorides, J.G. Norman, M.M. Murr, Liver injury during acute pancreatitis: the role of pancreatitis-associated ascitic fluid (paaf), p38-MAPK, and caspase-3 in inducing hepatocyte apoptosis, J. Gastrointest. Surg. 7 (2) (2003) 200-208, doi: http://dx.doi.org/10.1016/s1091-255x(02)00134-8.

[11] A.H. Lundberg, D.N. Granger, J. Russell, S. Callicutt, L.W. Gaber, M. Kotb, O. Sabek, A.O. Gaber, Temporal correlation of tumor necrosis factor-alpha release, upregulation of pulmonary ICAM-1 and VCAM-1, neutrophil sequestration, and lung injury in diet-induced pancreatitis, J. Gastrointest. Surg. 4 (3) (2000) 248-257, doi:http://dx.doi.org/10.1016/s1091-255x(00)80073-6.

[12] J.J. Easler, R. Mounzer, G.I. Papachristou, Pharmacological therapy for acute pancreatitis: where are we now? where are we going?, Minerva Gastroenterol. Dietol. 58 (4) (2012) 365-376.

[13] G. Fakhfouri, R. Rahimian, J.E. Ghia, W.I. Khan, A.R. Dehpour, Impact of 5-HT receptor antagonists on peripheral and central diseases, Drug Discov. Today 17 (13-14) (2012) 741-747, doi:http://dx.doi.org/10.1016/j.drudis.2012.02.009.

[14] G. Fakhfouri, K. Mousavizadeh, S.E. Mehr, A.R. Dehpour, M.R. Zirak, J.-E. Ghia, R. Rahimian, From chemotherapy-induced emesis to neuroprotection: therapeutic opportunities for 5- $\mathrm{HT}_{3}$ receptor antagonists, Mol. Neurobiol. 52 (3) (2014) 1670-1679, doi:http://dx.doi.org/10.1007/s12035-014-8957-5.

[15] K. Mousavizadeh, R. Rahimian, G. Fakhfouri, F. Aslani, P. Ghafourifar, Antiinflammatory effects of 5- $\mathrm{HT}_{3}$ receptor antagonist, tropisetron on experimental colitis in rats, Eur. J. Clin. Invest. (2009) 375-383.

[16] M.R. Zirak, R. Rahimian, M. Ghazi-Khansari, A. Abbasi, A. Razmi, S. Ejtemaei Mehr, K. Mousavizadeh, A.R. Dehpour, Tropisetron attenuates cisplatininduced nephrotoxicity in mice, Eur. J. Pharmacol. 738 (2014) 222-229, doi: http://dx.doi.org/10.1016/j.ejphar.2014.05.050.
[17] R. Rahimian, A. Daneshmand, S.E. Mehr, A. Barzegar-Fallah, S. MohammadiRick, G. Fakhfouri, A.P. Shabanzadeh, A.R. Dehpour, Tropisetron ameliorates ischemic brain injury in an embolic model of stroke, Brain Res. 1392 (2011) 101-109, doi:http://dx.doi.org/10.1016/j.brainres.2011.03.053.

[18] R. Rahimian, G. Fakhfouri, S. Ejtemaei Mehr, J.E. Ghia, A.A. Genazzani, B. Payandemehr, A.R. Dehpour, K. Mousavizadeh, D. Lim, Tropisetron attenuates amyloid-beta-induced inflammatory and apoptotic responses in rats, Eur. J. Clin. Invest. 43 (10) (2013) 1039-1051, doi:http://dx.doi.org/10.1111/eci.12141.

[19] A. Aminian, F. Noorbakhsh, M. Ghazi-Khansari, L. Kafami, S. Javadi, G. Hassanzadeh, R. Rahimian, A.R. Dehpour, S.E. Mehr, Tropisetron diminishes demyelination and disease severity in an animal model of multiple sclerosis, Neuroscience 248 (2013) 299-306, doi:http://dx.doi.org/10.1016/j. neuroscience.2013.06.009.

[20] D. Setoguchi, M. Nakamura, H. Yatsuki, E. Watanabe, Y. Tateishi, T. Kuwaki, S. Oda, Experimental examination of anti-inflammatory effects of a 5- $\mathrm{HT}_{3}$ receptor antagonist, tropisetron, and concomitant effects on autonomic nervous function in a rat sepsis model, Int. Immunopharmacol. 11 (12) (2011) 2073-2078, doi:http://dx.doi.org/10.1016/j.intimp.2011.08.022.

[21] E. Mazzon, T. Genovese, R. Di Paola, C. Muià, C. Crisafulli, G. Malleo, E. Esposito, R. Meli, E. Sessa, S. Cuzzocrea, Effects of 3-aminobenzamide, an inhibitor of poly (ADP-ribose) polymerase, in a mouse model of acute pancreatitis induced by cerulein, Eur. J. Pharmacol. 549 (1-3)(2006) 149-156, doi:http://dx.doi.org/ 10.1016/j.ejphar.2006.08.008.

[22] A. Abed, M. Minaiyan, A. Safaei, D. Taheri, Effect of diazepam on severity of acute pancreatitis: possible involvement of peripheral benzodiazepine receptors, ISRN Gastroenterol. 2013 (2013) 6, doi:http://dx.doi.org/10.1155/ $2013 / 484128$.

[23] S.W. Tsang, Y.-F. Guan, J. Wang, Z.-X. Bian, H.-J. Zhang, Inhibition of pancreatic oxidative damage by stilbene derivative dihydro-resveratrol: implication for treatment of acute pancreatitis, Sci. Rep. 6 (2016) 22859, doi:http://dx.doi.org/ $10.1038 /$ srep22859.

[24] A. Daneshmand, H. Mohammadi, R. Rahimian, P. Habibollahi, G. Fakhfouri, S.S. Talab, S.E. Mehr, A.R. Dehpour, Chronic lithium administration ameliorates 2,4,6-trinitrobenzene sulfonic acid-induced colitis in rats; potential role for adenosine triphosphate sensitive potassium channels, J. Gastroenterol. Hepatol. 26 (7) (2011) 1174-1181, doi:http://dx.doi.org/10.1111/j.14401746.2011.06719.x.

[25] I.-J. Jo, G.-S. Bae, S.B. Choi, D.-G. Kim, J.-Y. Shin, S.-H. Seo, M.-O. Choi, T.-H. Kim, H.-J. Song, S.-J. Park, Fisetin attenuates cerulein-induced acute pancreatitis through down regulation of JNK and NF- $\mathrm{KB}$ signaling pathways, Eur. J. Pharmacol. 737 (2014) 149-158, doi:http://dx.doi.org/10.1016/j. ejphar.2014.05.018.

[26] G. Fakhfouri, R. Rahimian, A. Daneshmand, A. Bahremand, M.R. Rasouli, A.R. Dehpour, S.E. Mehr, K. Mousavizadeh, Granisetron ameliorates acetic acidinduced colitis in rats, Hum. Exp. Toxicol. 29 (4) (2010) 321-328, doi:http://dx. doi.org/10.1177/0960327110362702.

[27] B. Güngör, K. Çağlayan, C. Polat, D. Şeren, K. Erzurumlu, Z. Malazgirt, The predictivity of serum biochemical markers in acute biliary pancreatitis, ISRN Gastroenterol. 2011 (2011) 279607, doi:http://dx.doi.org/10.5402/2011/ 279607.

[28] S.F. Gallagher, J. Yang, K. Baksh, K. Haines, H. Carpenter, P.K. Epling-Burnette, Y. Peng, J. Norman, M.M. Murr, Acute pancreatitis induces FasL gene expression and apoptosis in the liver1,2, J. Surg. Res. 122 (2) (2004) 201-209, doi:http:// dx.doi.org/10.1016/j.jss.2004.05.019.

[29] D. Altavilla, C. Famulari, M. Passaniti, M. Galeano, A. Macri, P. Seminara, L. Minutoli, H. Marini, M. Calo, F.S. Venuti, M. Esposito, F. Squadrito, Attenuated cerulein-induced pancreatitis in Nuclear Factor-kB-deficient mice, Lab. Invest. 83 (12) (2003) 1723-1732, doi:http://dx.doi.org/10.1097/01. LAB.0000101734.82054.BE.

[30] M.L. Malmstrom, M.B. Hansen, A.M. Andersen, A.K. Ersboll, O.H. Nielsen, L.N. Jorgensen, S. Novovic, Cytokines and organ failure in acute pancreatitis: inflammatory response in acute pancreatitis, Pancreas 41 (2) (2012) 271-277, doi:http://dx.doi.org/10.1097/MPA.0b013e3182240552.

[31] J. Mayer, B. Rau, F. Gansauge, H.G. Beger, Inflammatory mediators in human acute pancreatitis: clinical and pathophysiological implications, Gut 47 (4) (2000) 546-552, doi:http://dx.doi.org/10.1136/gut.47.4.546.

[32] A. Tsukamoto, T. Sugimoto, Y. Onuki, H. Shinoda, T. Mihara, M. Hori, T. Inomata, The $5-\mathrm{HT}_{3}$ receptor antagonist ondansetron attenuates pancreatic injury in cerulein-induced acute pancreatitis model, Inflammation (2017) 1-7, doi: http://dx.doi.org/10.1007/s10753-017-0584-7.

[33] R.K. Jha, Q. Ma, H. Sha, M. Palikhe, Acute pancreatitis: a literature review, Med. Sci. Monit. 15 (7) (2009) RA147-RA156.

[34] R. Rahimian, M.R. Zirak, M. Keshavarz, N. Fakhraei, A. Mohammadi-Farani, H. Hamdi, K. Mousavizadeh, Involvement of PPAR $\gamma$ in the protective action of tropisetron in an experimental model of ulcerative colitis, Immunopharmacol. Immunotoxicol. 38 (6) (2016) 432-440, doi:http://dx.doi.org/10.1080/ 08923973.2016.1231202.

[35] C. Stratz, H.S. Bhatia, R.S. Akundi, T. Nührenberg, D. Trenk, E. Muñoz, B.L. Fiebich, The anti-inflammatory effects of the $5-\mathrm{HT}_{3}$ receptor antagonist tropisetron are mediated by the inhibition of p38 MAPK activation in primary human monocytes, Int. Immunopharmacol. 13 (4) (2012) 398-402, doi:http:// dx.doi.org/10.1016/j.intimp.2012.05.013.

[36] V. Chaparro-Huerta, M.E. Flores-Soto, G. Gudiño-Cabrera, M.C. RiveraCervantes, O.K. Bitzer-Quintero, C. Beas-Zárate, Role of p38 MAPK and proinflammatory cytokines expression in glutamate-induced neuronal death of 
neonatal rats, Int. J. Dev Neurosci. 26 (5) (2008) 487-495, doi:http://dx.doi. org/10.1016/j.ijdevneu.2008.02.008.

[37] A.C.C. Wagner, W. Metzler, T. Höfken, H. Weber, B. Göke, P38 MAP kinase is expressed in the pancreas and is immediately activated following cerulein hyperstimulation, Digestion 60 (1) (1999) 41-47, doi:http://dx.doi.org/ $10.1159 / 000007587$.

[38] F.-C. Liu, H.-P. Yu, T.-L. Hwang, Y.-F. Tsai, Protective effect of tropisetron on rodent hepatic injury after trauma-hemorrhagic shock through p38 MAPKdependent hemeoxygenase-1 expression, PLoS One 7 (12) (2012) e53203, doi: http://dx.doi.org/10.1371/journal.pone.0053203.

[39] J. Branger, B. van den Blink, S. Weijer, J. Madwed, C.L. Bos, A. Gupta, C.-L. Yong, S. H. Polmar, D.P. Olszyna, C.E. Hack, S.J.H. van Deventer, M.P. Peppelenbosch, T van der Poll, Anti-inflammatory effects of a p38 mitogen-activated protein kinase inhibitor during human endotoxemia, J. Immunol. 168 (8) (2002) 40704077, doi:http://dx.doi.org/10.4049/jimmunol.168.8.4070.

[40] A.R. Clark, J.L.E. Dean, J. Saklatvala, The p38 MAPK pathway mediates both antiinflammatory and proinflammatory processes: comment on the article by Damjanov and the editorial by Genovese, Arthritis Rheum. 60 (11) (2009) 3513-3514, doi:http://dx.doi.org/10.1002/art.24919.

[41] R. Pezzilli, A.M. Morselli-Labate, R. Corinaldesi, NSAIDS and acute pancreatitis: a systematic review, Pharmaceuticals 3 (3) (2010) 558, doi:http://dx.doi.org/ 10.3390/ph3030558.

[42] K. Okamoto, H. Imbe, A. Tashiro, S. Kumabe, E. Senba, Blockade of peripheral $5 \mathrm{HT}_{3}$ receptor attenuates the formalin-induced nocifensive behavior in persistent temporomandibular joint inflammation of rat, Neurosci. Lett. 367 (2) (2004) 259-263, doi:http://dx.doi.org/10.1016/j.neulet.2004.06.

[43] W. Mei, M. Li, Y. Yu, C.W. Cheung, F. Cao, B. Nie, Z. Zhang, P. Wang, Y. Tian, Tropisetron alleviate early post-operative pain after gynecological laparoscopy in sevoflurane based general anaesthesia: a randomized, parallel-group factorial study, Eur. J. Pain 18 (2) (2014) 238-248, doi:http://dx.doi.org/ 10.1002/j.1532-2149.2013.00365.x.

[44] F. Nasirinezhad, M. Hosseini, Z. Karami, M. Yousefifard, A. Janzadeh, Spinal 5 $\mathrm{HT}_{3}$ receptor mediates nociceptive effect on central neuropathic pain; possible therapeutic role for tropisetron, J. Spinal Cord Med. 39 (2) (2016) 212-219, doi: http://dx.doi.org/10.1179/2045772315y.0000000047.

[45] P.G. Lankisch, T. Blum, A. Bruns, M. Dröge, G. Brinkmann, K. Struckmann, M Nauck, P. Maisonneuve, A.B. Lowenfels, Has blood glucose level measured on admission to hospital in a patient with acute pancreatitis any prognostic value? Pancreatology 1 (3) (2001) 224-229, doi:http://dx.doi.org/10.1159/ 000055815.

[46] S.L.M. Das, P.P. Singh, A.R.J. Phillips, R. Murphy, J.A. Windsor, M.S. Petrov, Newly diagnosed diabetes mellitus after acute pancreatitis: a systematic review and meta-analysis, Gut 63 (5) (2014) 818-831, doi:http://dx.doi.org/10.1136/ gutjnl-2013-305062.

[47] R. Rahimian, S. Ejtemaei Mehr, G. Fakhfouri, A.R. Dehpour, 5-HT 3 receptor antagonists: new promising therapeutic agents in diabetes and its complications, Acta Med. Iran. 51 (10) (2013) 736.

[48] F. Carvalho, D. Macêdo, I. Bandeira, I. Maldonado, L. Salles, M.F. Azevedo, J.B. Rocha Jr, E. De Castro-e-Silva, Central 5- $\mathrm{HT}_{3}$ receptor stimulation by m-CPBC increases blood glucose in rats, Horm. Metab. Res. 34 (02) (2002) 55-61, doi: http://dx.doi.org/10.1055/s-2002-20525.

[49] K. Heimes, B. Feistel, E.J. Verspohl, Impact of the 5- $\mathrm{HT}_{3}$ receptor channel system for insulin secretion and interaction of ginger extracts, Eur. J.
Pharmacol. 624 (1-3) (2009) 58-65, doi:http://dx.doi.org/10.1016/j. ejphar.2009.09.049.

[50] P. Proks, F. Reimann, N. Green, F. Gribble, F. Ashcroft, Sulfonylurea stimulation of insulin secretion, Diabetes 51 (Suppl. 3) (2002) S368.

[51] T. Frick, C. Fernandez-del-Cas, D. Bimmler, A. Warshaw, Elevated calcium and activation of trypsinogen in rat pancreatic acini, Gut 41 (3) (1997) 339-343, doi:http://dx.doi.org/10.1136/gut.41.3.339.

[52] D. Awla, A.V. Zetterqvist, A. Abdulla, C. Camello, L.M. Berglund, P. Spégel, M.J. Pozo, P.J. Camello, S. Regnér, M.F. Gomez, H. Thorlacius, NFATc3 regulates trypsinogen activation, neutrophil recruitment, and tissue damage in acute pancreatitis in mice, Gastroenterology 1360 (2012) e7, doi:http://dx.doi.org/ 10.1053/j.gastro.2012.07.098.

[53] J. Aramburu, F. García-Cózar, A. Raghavan, H. Okamura, A. Rao, P.G. Hogan, Selective inhibition of NFAT activation by a peptide spanning the calcineurin targeting site of NFAT, Mol. Cell 1 (5) (1998) 627-637, doi:http://dx.doi.org/ 10.1016/S1097-2765(00)80063-5.

[54] F. Asadi, A. Razmi, A.R. Dehpour, M. Shafiei, Tropisetron inhibits high glucoseinduced calcineurin/NFAT hypertrophic pathway in H9c2 myocardial cells, J. Pharm. Pharmacol. 68 (4) (2016) 485-493, doi:http://dx.doi.org/10.1111/ jphp.12522.

[55] R. Rahimian, A.R. Dehpour, G. Fakhfouri, M.R. Khorramizadeh, J.-E. Ghia, M. Seyedabadi, A. Caldarelli, K. Mousavizadeh, M. Forouzandeh, S.E. Mehr Tropisetron upregulates cannabinoid CB1 receptors in cerebellar granule cells: possible involvement of calcineurin, Brain Res. 2011 (1417) 1-8, doi:http://dx. doi.org/10.1016/j.brainres.2011.08.050.

[56] L. Vega Lde, E. Munoz, M.A. Calzado, K. Lieb, E. Candelario-Jalil, H. Gschaidmeir,

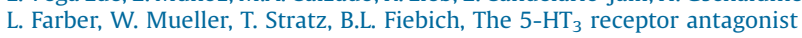
tropisetron inhibits $\mathrm{T}$ cell activation by targeting the calcineurin pathway, Biochem. Pharmacol. 70 (3) (2005) 369-380, doi:http://dx.doi.org/10.1016/j. bcp.2005.04.031.

[57] A. Stegemann, M. Böhm, The $\alpha 7$ nicotinic acetylcholine receptor agonist tropisetron counteracts UVA-mediated oxidative stress in human dermal fibroblasts, Exp. Dermatol. 25 (12) (2016) 994-996, doi:http://dx.doi.org/ 10.1111/exd.13220 n/a-n/a.

[58] J.E. Macor, D. Gurley, T. Lanthorn, J. Loch, R.A. Mack, G. Mullen, O. Tran, N. Wright, J.C. Gordon, The 5- $\mathrm{HT}_{3}$ antagonist tropisetron (ICS 205-930) is a potent and selective $\alpha 7$ nicotinic receptor partial agonist, Bioorg. Med. Chem. Lett. 11 (3) (2001) 319-321, doi:http://dx.doi.org/10.1016/S0960-894X(00)00670-3.

[59] C.A. Báez-Pagán, M. Delgado-Vélez, J.A. Lasalde-Dominicci, Activation of the macrophage á7 nicotinic acetylcholine receptor and control of inflammation, J. Neuroimmune Pharmacol. 10 (3) (2015) 468-476, doi:http://dx.doi.org/ 10.1007/s11481-015-9601-5.

[60] L. Yi, J.-f. Luo, B.-b. Xie, J.-X. Liu, J.-y. Wang, L. Liu, P.-x. Wang, H. Zhou, Y. Dong, $\alpha 7$ nicotinic acetylcholine receptor is a novel mediator of sinomenine antiinflammation effect in macrophages stimulated by lipopolysaccharide, Shock 44 (2) (2015) 188-195, doi:http://dx.doi.org/10.1097/ shk.0000000000000389.

[61] H. Huang, Y. Liu, J. Daniluk, S. Gaiser, J. Chu, H. Wang, Z.S. Li, C.D. Logsdon, B. Ji, Activation of nuclear factor- $\kappa \mathrm{B}$ in acinar cells increases the severity of pancreatitis in mice, Gastroenterology 144 (1) (2013) 202-210, doi:http://dx. doi.org/10.1053/j.gastro.2012.09.059. 